\title{
A Facile and Effective Electrochemical DNA Biosensor for the Detection of GardnerellaVaginalis Based on One-Step BSA Blocked Electrode
}

\author{
Zongfu Zheng ${ }^{1,3, *}$, Jicheng Jiang ${ }^{1,3}$, Meilin Zheng ${ }^{1,3}$, Chengfei Zhao ${ }^{2}$, Kai Peng ${ }^{1}$, Xinhua Lin ${ }^{2}$, \\ Shaohuang Weng, ${ }^{2, *}$ \\ ${ }^{1} 476$ Hospital of PLA, Fuzhou, 350002, China \\ ${ }^{2}$ Department of Pharmaceutical Analysis, Faculty of Pharmacy, Fujian Medical University, Fuzhou, \\ 350108, China \\ ${ }^{3}$ Affiliated Dongfang Hospital, Xiamen University, Fuzhou, 350025, China \\ *E-mail: fuhos_476@126.com, shweng@ fjmu.edu.cn
}

doi: $10.20964 / 2016.10 .31$

Received: 24 June2016/ Accepted: 4 August 2016 / Published: 6 September 2016

An electrochemical biosensor based on bovine serum albumin blocked functional electrode (BSA-E) for the precise detection of specific gene of GardnerellaVaginalis was developed in this work. BSA assembled gold electrode was used for constructing the electrochemical sandwich-type DNA biosensor to achieve excellent sensitivity, good reproducibility. And a low detection limit of $0.5 \mathrm{pM}$ and a wide linear range were obtained under optimized condition. The wonderful performance of the proposed sensor was attributed to the application of BSA which could effectively to prevent the possible nonspecific adsorption of target DNA and protein (avidin-HRP) on the surface of Au electrode. The proposed approach provides another effect choice for the determination of GardnerellaVaginalis.

Keywords:GardnerellaVaginalis; Electrochemical DNA biosensor; Amperometric i-t curve; Bovine serum albumin; Gold electrode

\section{$\underline{\text { FULL TEXT }}$}

(C) 2016 The Authors. Published by ESG (www.electrochemsci.org). This article is an open access article distributed under the terms and conditions of the Creative Commons Attribution license (http://creativecommons.org/licenses/by/4.0/). 